\title{
Growth and Extended Survival of Escherichia coli 0157:H7 in Soil Organic Matter
}

\author{
Gitanjali NandaKafle ${ }^{1}$, Amy A. Christie ${ }^{1}$, Sébastien Vilain ${ }^{2,3}$ and Volker S. Brözel ${ }^{1,4 *}$ \\ ${ }^{1}$ Department of Biology and Microbiology, South Dakota State University, Brookings, SD, United States, ${ }^{2}$ Spectrométrie de \\ Masse des Macromolécules Biologiques, Chimie Biologie des Membranes et Nanoobjets, UMR Centre National de la \\ Recherche Scientifique 5248, Institut National Polytechnique de Bordeaux, Université de Bordeaux, Bordeaux, France, \\ ${ }^{3}$ Plateforme Protéome, Centre Génomique Fonctionnelle de Bordeaux, Université de Bordeaux, Bordeaux, France, \\ ${ }^{4}$ Department of Biochemistry, Genetics and Microbiology, University of Pretoria, Gauteng, South Africa
}

\section{OPEN ACCESS}

Edited by:

Satoshi Tsuneda,

Waseda University, Japan

Reviewed by:

Leticia Veronica Bentancor, Universidad Nacional de Quilmes

(UNQ), Argentina

Chitrita Debroy,

Pennsylvania State University,

United States

${ }^{*}$ Correspondence:

Volker S. Brözel

volker.broze/@sdstate.edu

Specialty section:

This article was submitted to Microbial Physiology and Metabolism,

a section of the journal

Frontiers in Microbiology

Received: 02 January 2018 Accepted: 04 April 2018

Published: 23 April 2018

Citation:

NandaKafle G, Christie AA, Vilain S and Brözel VS (2018) Growth and

Extended Survival of Escherichia coli

0157:H7 in Soil Organic Matter.

Front. Microbiol. 9:762.

doi: 10.3389/fmicb.2018.00762
Enterohaemorrhagic Escherichia coli, such as serotype O157:H7, are a leading cause of food-associated outbreaks. While the primary reservoir is associated with cattle, plant foods have been associated as sources of human infection. E. coli is able to grow in the tissue of food plants such as spinach. While fecal contamination is the primary suspect, soil has been underestimated as a potential reservoir. Persistence of bacterial populations in open systems is the product of growth, death, predation, and competition. Here we report that E. coli $\mathrm{O} 157: \mathrm{H} 7$ can grow using the soluble compounds in soil, and characterize the effect of soil growth on the stationary phase proteome. E. coli 933D (stx/l-) was cultured in Soil Extracted Soluble Organic Matter (SESOM) and the culturable count determined for $24 \mathrm{~d}$. The proteomes of exponential and stationary phase populations were characterized by 2D gel electrophoresis and protein spots were identified by MALDI-TOF mass spectrometry. While LB controls displayed a death phase, SESOM grown population remained culturable for $24 \mathrm{~d}$, indicating an altered physiological state with superior longevity. This was not due to decreased cell density on entry to stationary phase as $24 \mathrm{~h}$ SESOM populations concentrated 10 -fold retained their longevity. Principal component analysis showed that stationary phase proteomes from SESOM and LB were different. Differences included proteins involved in stress response, motility, membrane and wall composition, nutrient uptake, translation and protein turnover, and anabolic and catabolic pathways, indicating an altered physiological state of soil-grown cells entering stationary phase. The results suggest that $E$. coli may be a soil commensal that, in absence of predation and competition, maintains stable populations in soil.

Keywords: Escherichia coli 0157:H7, soil organic matter, stationary phase, survival, proteome

\section{INTRODUCTION}

Escherichia coli $\mathrm{O} 157: \mathrm{H} 7$ and related enterohaemorrhagic strains have been associated with many serious food-associated outbreaks (Hilborn et al., 1999; Currie et al., 2007; Grant et al., 2008; King et al., 2009). The infectious dose is low so that food products are required to be free from enterohaemorrhagic Escherichia coli O157:H7, but despite various measures taken during 
processing, consumers can still be exposed to this pathogen (LeBlanc, 2003; Yang et al., 2017). Cattle are widely believed to be the primary host and several outbreaks have been associated with beef-based products (Currie et al., 2007; King et al., 2009). E. coli $\mathrm{O} 157: \mathrm{H7}$ is known to be associated with the bovine gastrointestinal tract, specifically the cecum (Yoon and Hovde, 2008; Wang et al., 2017), currently believed to be the primary source of entry into the food chain. More recently various plant foods such as spinach, tomato, lettuce, and fresh fruits have been identified as sources (Grant et al., 2008; Herman et al., 2015; Denis et al., 2016). Initially these foods were thought to be fecally contaminated, but recent reports suggest growth of $E$. coli O157:H7 (Brandl, 2008; Wright et al., 2013, 2017) in tissues of salad leaves and tomatoes. Upon inoculation from an unknown source, the enteric bacteria multiply inside the growing plant, and cannot be removed through surface treatment such as washing. The annual nature of these crop plants excludes them as an environmental reservoir of these enteric bacteria. Rather, these crop plants would need to be infected during growth.

E. coli are found in both gastrointestinal systems, and in the environment (Adamowicz et al., 1991; Ishii et al., 2006; Ksoll et al., 2007). Once shed from a mammalian host, E. coli populations are widely believed to enter a dead end, relying for extended survival on stress responses (Winfield and Groisman, 2003). The paradigm assumes slow decline following fecal contamination, the basis of the fecal coliform test (Tallon et al., 2005). This is supported by decline of E. coli O157:H7 in manure (Williams et al., 2008; Looper et al., 2009) and in soil (Berry and Miller, 2005) over time. Yet enterohaemorrhagic E. coli maintain culturable populations in various soils for many months, even where moisture is limited, and with slower decline at lower temperatures (Berry and Miller, 2005; Fremaux et al., 2008). Some E. coli appear to grow in sub-tropical environments such as riverbank soil and river sediment (Desmarais et al., 2002). More recently persistent $E$. coli populations have been reported from temperate forest, watershed soils (Byappanahalli et al., 2006; Ishii et al., 2006), and pasture (NandaKafle et al., 2017). Naturalized E. coli strains believed to be autochthonous to soil were able to maintain populations in soils from Lake Superior shore.

Persistence of bacterial populations in soil would require a suitable nutrient pool. Soil is a complex assemblage of particulate components with varying concentrations of organic and inorganic matter. The dissolved organic matter (DOM) in soils is a cocktail of sugars, aromatic compounds, amino acids, and organic and fatty acids between $\mathrm{C}_{14}$ and $\mathrm{C}_{54}$ (Huang et al., 1998; Kalbitz et al., 2000). The concentrations of solutes like amino acids range from 0.1 to $5 \mu \mathrm{M}$. Monoprotic acids (e.g., formate, acetate and lactate) range from 1 to $1,000 \mu \mathrm{M}$, and diand trivalent low molecular organic acids (e.g., oxalate, malate and citrate) from 0.1 to $50 \mu \mathrm{M}$ (Strobel, 2001; Pizzeghello et al., 2006). Monomeric intermediates such as carboxylic acids and amino acids have residence times in the order of hours in soils (Jones et al., 2005; Van Hees et al., 2005). Carbohydrates like mono-, di-, and oligosaccharides vary in presence and concentration (Lynch, 1982; Guggenberger and Zech, 1993a,b; Kaiser et al., 2001; Kalbitz et al., 2003). Surprisingly, glucose is present in soils up to $100 \mu \mathrm{M}$ concentrations (Schneckenberger et al., 2008). The variety of sugars, and organic and amino acids in these soils suggests that enteric bacteria should, generally, be able to grow here. We have reported a detailed analysis of liquid extract of deciduous forest soil, able to support growth of Salmonella Typhimurium (Liebeke et al., 2009).

The source of contamination of annual food crops by enterrohaemorrhagic E. coli is unresolved. Soil has been underestimated as a potential reservoir. As persistence of bacterial populations in open systems is the product of growth, death, predation, and competition, measurement of numbers over time shows the overall net effect, and cannot inform autecology of the species. It is unclear whether population maintenance of E. coli O157:H7 in soils is due to a combination of cell division and death, predation and competition, or simply to extended survival alone. It has been shown that E. coli O157:H7 is able to grow in sterile fresh water (Vital et al., 2008). The aim of our work was to determine whether enterrohaemorrhagic E. coli are able to grow using nutrients available in soil. Here we report that E. coli O157:H7 is able to grow in liquid extract of soil. Furthermore, soil extract-grown populations demonstrate extended culturability over cultures grown in laboratory media, and display a unique stationary phase proteome.

\section{MATERIALS AND METHODS}

\section{Culture and Culture Media}

The partially attenuated E. coli O157:H7 933D (stx-II) (Strockbine et al., 1986) was maintained in 50\% (v/v) glycerol at $-80^{\circ} \mathrm{C}$. This strain still expresses stxI (O’Brien et al., 1989). Presence of the stxI gene was confirmed by PCR (Fagan et al., 1999), and the amplicons confirmed by DNA sequencing. Soils used were corn field soil (Brandt silty clay loam, Aurora, South Dakota, USA), a commercially available garden top soil, and deciduous forest soil (Oak Lake Field Station, Brookings, South Dakota, USA). Cow manure from a herd fed an antibiotic-free diet was obtained from the South Dakota State University Beef Unit. Soil-extracted solubilized organic matter (SESOM) was prepared as described previously (Vilain et al., 2006). Briefly, $100 \mathrm{~g}$ of air-dried soil, or $90 \mathrm{~g}$ soil and $10 \mathrm{~g}$ manure, was suspended in $500 \mathrm{~mL}$ MOPS buffer $\left(10 \mathrm{mM}, \mathrm{pH} 7,50^{\circ} \mathrm{C}\right)$ and kept shaking at $200 \mathrm{rpm}$ for $1 \mathrm{~h}$. The extracts were filtered sequentially through filter paper, hydrophilic PVDF membranes with $5,1.2$, and $0.45 \mu \mathrm{m}$, pore sizes to remove particulates, and sterilized using a polyethersulfone membrane with a $0.22 \mu \mathrm{m}$ pore size. The sterility of each batch was determined by placing 5 $\mu \mathrm{l} \mathrm{SESOM}$ onto LB agar plates and incubating at $30^{\circ} \mathrm{C}$ for $24 \mathrm{~h}$.

\section{Culturing Conditions}

Growth and survival in the various liquid extracts was determined by measuring the optical density periodically. Overnight cultures of E. coli O157:H7 were prepared in LB broth, diluted 1:1,000 into $50 \mathrm{~mL}$ fresh $\mathrm{LB}$ broth and incubated to midexponential phase at $28^{\circ} \mathrm{C}\left(3 \mathrm{~h}, \mathrm{~A}_{546}=0.41\right)$. Cells were harvested by centrifugation $\left(10,000 \times \mathrm{g}, 10 \mathrm{~min}, 30^{\circ} \mathrm{C}\right)$, washed twice, and re-suspended in $2 \mathrm{~mL}$ sterile tap water. Triplicate $250 \mathrm{~mL}$ flasks with $50 \mathrm{~mL}$ pre-warmed liquid medium (LB, 1/40th strength LB and SESOM from deciduous forest soil) were inoculated to 
an initial $\mathrm{A}_{546}$ of 0.005 , and incubated at $28^{\circ} \mathrm{C}$ while shaking (120 rpm). The culturable count was determined every hour till $8 \mathrm{~h}$, at $24 \mathrm{~h}$ and daily till $24 \mathrm{~d}$ by the droplet plate technique (Lindsay and von Holy, 1999). Briefly, $20 \mu \mathrm{L}$ volumes of serial dilutions were plated onto LB agar and incubated for $18 \mathrm{~h}$ at $30^{\circ} \mathrm{C}$. Culturable counts reflected the average of nine droplet counts, with three droplet counts from each of three replicate cultures. The homogeneity of variance was checked at $1 \mathrm{~d}$, and then every 4 days till $24 \mathrm{~d}$. There was no reason to reject the null hypothesis, meaning that homogeneity of variance of CFU of three media was equal. Thus, the data were subjected to an ANOVA test with multiple LSD comparison using Statistix 9.0.5 (Informer Technologies, Inc.).

\section{Effect of Cell Density on Culturability}

The effect of cell density on extended culturability of populations was investigated by concentrating or diluting populations, and re-suspending in cell-free supernatants of the same culture type. LB-grown populations were harvested at $24 \mathrm{~h}$ of incubation $\left(10,000 \times \mathrm{g}, 10 \mathrm{~min}, 30^{\circ} \mathrm{C}\right)$ and re-suspended to one tenth their density in cell-free supernatant. Conversely, $1 / 40$ th strength LB and SESOM-grown populations were re-suspended to 10 -fold density in their respective cell-free supernatants. All cultures were then incubated at $28^{\circ} \mathrm{C}$ while shaking, and the culturable count determined every $24 \mathrm{~h}$ to day 24 . Culturable counts reflected the average of nine droplet counts, with three droplet counts from each of three replicate cultures. Statistical analysis was performed as described above.

\section{Protein Sample Preparation}

SESOM and LB-grown populations of E. coli O157:H7 were harvested in mid-exponential phase (180 and $140 \mathrm{~min}$ ) at $\mathrm{A}_{546}$ 0.055 and 0.183 , respectively, and SESOM, LB, and 1/40th strength LB populations were harvested in late stationary phase $(3 \mathrm{~d})$. Cells were harvested by centrifugation $(10,000 \times \mathrm{g}, 10 \mathrm{~min}$, $\left.4^{\circ} \mathrm{C}\right)$, washed in $5 \mathrm{~mL}$ potassium phosphate buffer $(100 \mathrm{mM}$, $\mathrm{pH} 7.0$ ), and re-suspended in $2 \mathrm{ml}$ IEF buffer ( $7 \mathrm{M}$ urea, $2 \mathrm{M}$ thiourea, 2\% (w/v) 3-[3-chloamidopropyl] dimethylammonio1-propanesulfonate (CHAPS), 2\% (w/v) Amidosulfobetaine-14 (ASB14), $10 \mathrm{mM}$ dithiothreitol (DTT), and 2\% (v/v) carrier ampholytes (pH 3.5-10; Amersham)). Cells were disrupted by two cycles of freeze thaw (from $-80^{\circ} \mathrm{C}$ to $20^{\circ} \mathrm{C}$ ) followed by ultrasonication at $4^{\circ} \mathrm{C}(15 \mathrm{~W}, 12$ pulses of $3 \mathrm{~min})$. Cell debris was removed by centrifugation $(10,000 \times \mathrm{g}, 10 \mathrm{~min})$, and the protein concentration was determined using the Bradford protein assay (BioRAD), with bovine serum albumin as the standard (Vilain et al., 2001). Each sample type was prepared on three separate occasions, to yield three separate protein extracts.

\section{Two-Dimensional Gel Electrophoresis (2DE)}

IPG strips (pH 4-7, $18 \mathrm{~cm}$, GE Healthcare) were re-hydrated for $16 \mathrm{~h}$ with $400 \mu \mathrm{L}$ IEF buffer containing $50 \mu \mathrm{g}$ protein for $2 \mathrm{D}$ gel map construction, and $200 \mu \mathrm{g}$ protein per IPG strip for protein identification. Proteins were separated by IEF on an Amersham Pharmacia horizontal electrophoresis system for a total of $44 \mathrm{kVh}$ $(150 \mathrm{~V}$ for $1 \mathrm{~h}, 350 \mathrm{~V}$ for $1 \mathrm{~h}, 500 \mathrm{~V}$ for $4 \mathrm{~h}, 750 \mathrm{~V}$ for $1 \mathrm{~h}, 1 \mathrm{kV}$ for $1 \mathrm{~h}, 1.5 \mathrm{kV}$ for $1 \mathrm{~h}$ and $3.5 \mathrm{kV}$ for $11 \mathrm{~h}$ ). After IEF, the IPG gel strips were frozen at $-80^{\circ} \mathrm{C}$, thawed and equilibrated for $10 \mathrm{~min}$ in equilibration buffer (6 M urea and 30\% glycerol, $1 \%$ SDS) with $20 \mathrm{mg} / \mathrm{mL}$ DTT, and for $10 \mathrm{~min}$ in equilibration buffer with $260 \mathrm{mM}$ iodoacetamide. The second dimension consisted of SDS-PAGE using a $12.5 \%(\mathrm{w} / \mathrm{v})$ running polyacrylamide gel and a $4.65 \%$ stacking gel (width, $18 \mathrm{~cm}$; length, $20 \mathrm{~cm}$; thickness, $1 \mathrm{~mm}$ ). Gels were stained with silver (Rabilloud, 1992) for spot detection and protein map construction, and with colloidal Coomassie Blue G250 for protein identification (Vilain et al., 2001). Uninoculated SESOM was run on a one-dimensional SDS PAGE to check for proteins present, but following staining, none were found.

\section{Gel Analysis, Spot Detection, and Protein Map Construction}

Three gels of each sample type, prepared from separate cultures and extracts, were scanned using a transmission scanner (ScanMaker 9800XL, Microtek) in transmission mode. Gel images were analyzed using PDQuest software (version 7.3.1; Bio-Rad) which allows detection, quantification and matching of protein spots. Spots were quantified on a Gaussian image and pooled on a reference image. The following formula was used to calculate the quantity of Gaussian spot: Spot height $\times \sigma_{\mathrm{x}} \times \sigma_{\mathrm{y}} \times$ $\pi$; where: Spot height is the peak of the Gaussian representation of the spot, $\sigma_{\mathrm{x}}$ is the standard deviation of the Gaussian distribution of the spot in the direction of the $\mathrm{x}$ axis, and $\sigma_{\mathrm{y}}$ is the standard deviation in the direction of the y axis. SESOM-derived spots either higher than 2-fold or less than half the intensity in LB broth were excised from stationary phase LB, LB $1 / 40$, and SESOM derived gels, and identified by MALDI-TOF mass spectrometry of tryptic digests as described previously (Voigt et al., 2006), but using the E. coli O157:H7 EDL933 sequence database (ftp://www.expasy.org/databases/complete_proteomes/ fasta).

Principal component analysis (PCA) of the 2D electrophoretograms was performed as described previously (Vilain and Brözel, 2006), using Statgraphics Plus 4.0 (Manugistics). Briefly, calculations of the Eigen value were comprised by taking the data set and subtracting the mean value from each dimension (ie., effect of culture medium) until all means were zero. A covariance matrix was then calculated since the data set has more than one dimension. By calculating the covariance matrix on means of zero a line develops that characterizes the data. The lines, or Eigen values, determine the statistical significance of each of the components.

\section{RESULTS}

The enterohaemorrhagic pathogen E. coli O157:H7 was able to grow using water-soluble organic matter from various soils, as indicated by increases in optical density during incubation (Figure 1). The yield in SESOM was 1 Log lower than in LB broth, and varied among extracts of various soils. Nutrient carryover from the LB-pre-culture was avoided by extensive washing and inoculating to a low initial density of $A_{546}=0.005$. These 


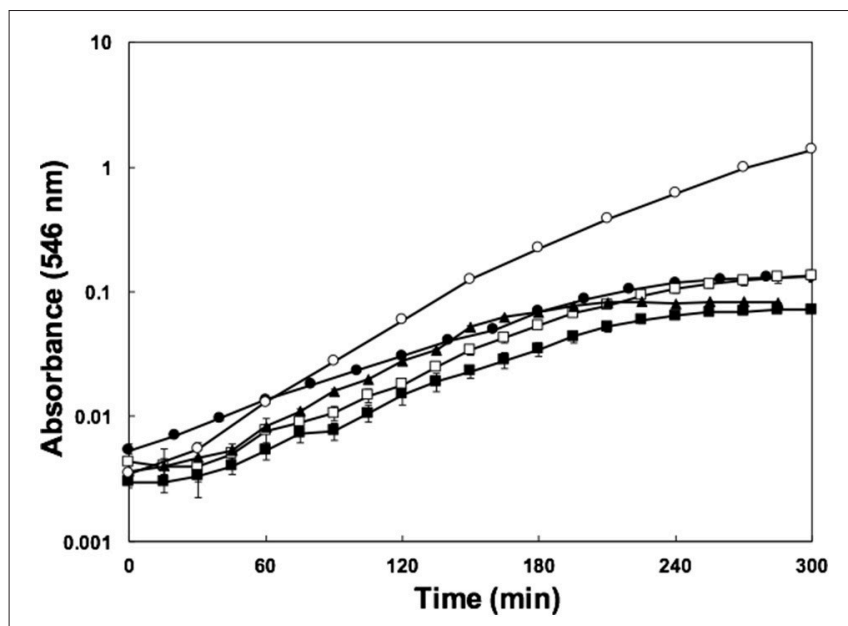

FIGURE 1 | Growth of E. coli 0157:H7 933D stxll- in SESOM from deciduous forest soil $(\mathbf{\bullet})$, corn field soil (घ), corn field soil supplemented with $10 \%(\mathrm{~m} / \mathrm{v})$ cow manure $(\square)$, garden soil $(\boldsymbol{\Delta})$, and LB broth $(\mathrm{O})$ while shaking at $30^{\circ} \mathrm{C}$.

results indicate that, in the absence of competition and predation, populations of E. coli O157:H7 933D should be able to grow and divide in soils, as supported by population increases in the various SESOM evaluated. Populations in LB broth started losing culturability after $3 \mathrm{~d}$ of incubation, with long-term stationary phase of $1 \%$ of the population density setting in on $\mathrm{d} 9$, as is well established. Surprisingly, SESOM-grown populations remained culturable for $24 \mathrm{~d}$, the duration of the experiment (Figure 2A). The observed loss of culturability in LB was not due to an adverse $\mathrm{pH}$, measured as 6.8 (d16) and 7.3 (d19). The $\mathrm{pH}$ of uninoculated SESOM was 6.8, decreasing to 5.9 (d16) and 5.8 (d19). Maintenance of the stxI gene in SESOM and LB-grown cultures was confirmed by PCR before, and at the end of the $24 \mathrm{~d}$ incubation period (data not shown).

To determine whether cell density during entry into stationary phase affects future culturability, we sought to culture in LB to the same population density achieved in SESOM. Various dilutions of $\operatorname{LB}(1 / 30,1 / 40,1 / 50,1 / 70$, and 1/100) were evaluated to determine which supported a final optical density similar to SESOM (results not shown). LB diluted 40 times yielded the desired density after $24 \mathrm{~h}$, as in SESOM, and the resulting populations remained culturable longer than in $L B$, with a stable population of $10^{8} \mathrm{CFU} / \mathrm{mL}$ at $\mathrm{d} 9$ (Figure 2A), after which culturability declined as in LB. In contrast, SESOM cultures remained culturable, significantly greater than in LB or 1/40th strength LB (Figure 2A). This indicated that population density in stationary phase may play a role in maintenance of culturability of cells, with higher density associated with decreased survival. The $\mathrm{pH}$ on $\mathrm{d} 12$ was 6.6. Cells that entered stationary phase due to nutrient limitation in $1 / 40$ th strength LB were more resilient than populations grown to higher density in LB. SESOM grown cells were, however, more resilient than $1 / 40$ th LB grown cells, although both entered stationary phase due to nutrient limitation (Figure 2A). This indicated that soil grown E. coli populations would persist longer in soil than predicted by laboratory experiments. Cultures in M9 minimal medium with 10 g. $\mathrm{L}^{-1}$ glucose displayed loss in culturability over time, similar to in LB (data not shown), indicating that increased longevity could not be attributed to growth requiring a greater degree of anabolic reactions.

Cell density appeared to play a role in stationary phase survival of LB-grown populations (Figure 2A). To further investigate the role of cell density in survival, we modified cell density 10 -fold upon entry into stationary phase. LB-grown stationary phase cells $(24 \mathrm{~h})$ were harvested and resuspended to one tenth their original density in their own spent broth, and the culturable count determined for $24 \mathrm{~d}$. The population lost one $\log _{10}$ of culturability after $\mathrm{d} 4$ (Figure $2 \mathbf{B}$ ), as opposed to $2 \log _{10}$ in undiluted culture (Figure 2A). This could indicate that LB-grown E. coli are able to maintain only a certain cell density into stationary phase. To determine whether the resilience of populations grown in $1 / 40$ strength LB was due to lower final density, stationary phase populations were concentrated 10-fold and resuspended in their own supernatant. The increased cell density did not initially lead to much loss of culturability, similar to the un-concentrated culture (Figures 2A,B). After decline at d8, late stationary phase population density remained at 10 -fold that of the original 1/40th LB grown culture. Importantly, the concentrated 1/40th $\mathrm{LB}$ population was at the same density as LB-grown population entering stationary phase, but did not undergo the $2 \log _{10}$ decline. Thus 1/40th LB-grown cells were more likely to survive than LB-grown ones, irrespective of cell density post-stationary phase. These results indicated that conditions upon entry into stationary phase affect the condition of the cells, thereby determining their potential for survival over long term incubation.

SESOM-grown populations maintained a 10-fold concentration in their own spent medium, and declined slowly, only showing a 5-fold decline at d19 (Figure 2B). The SESOM population remained significantly greater than the 140th strength LB population. Thus SESOM-grown cells were more likely to survive than $1 / 40$ th and LB-grown ones, irrespective of cell density post-stationary phase. Collectively the results indicated that extended longevity of SESOM-grown populations was due to both a lower cell density, but also to a SESOMassociated factor. These results suggested that SESOM-grown populations had an altered physiological state when entering stationary phase.

To gain insight into possible physiological reasons underlying the extended longevity of SESOM-grown populations, the proteomes of LB and SESOM-grown cultures in exponential and stationary phase $(\mathrm{d} 3)$, were determined by $2 \mathrm{DE}$, and compared to the $1 / 40$ th LB stationary phase proteome. For exponential phase, care was taken that populations had not yet begun transition to stationary phase. The five proteomic datasets were then subjected to principle component analysis (PCA). Four components were revealed at an Eigen value greater than 1, viz. 2.69, 2.51, 1.53, and 1.20. These components were sequentially compared in pairwise fashion using biplots (Figure 3). The results showed that exponential phase LB- and SESOM grown populations differed significantly, as did stationary phase populations in the two media. Intriguingly, the LB $1 / 40$ th stationary proteome was very similar to the SESOM-proteome in the first three of 

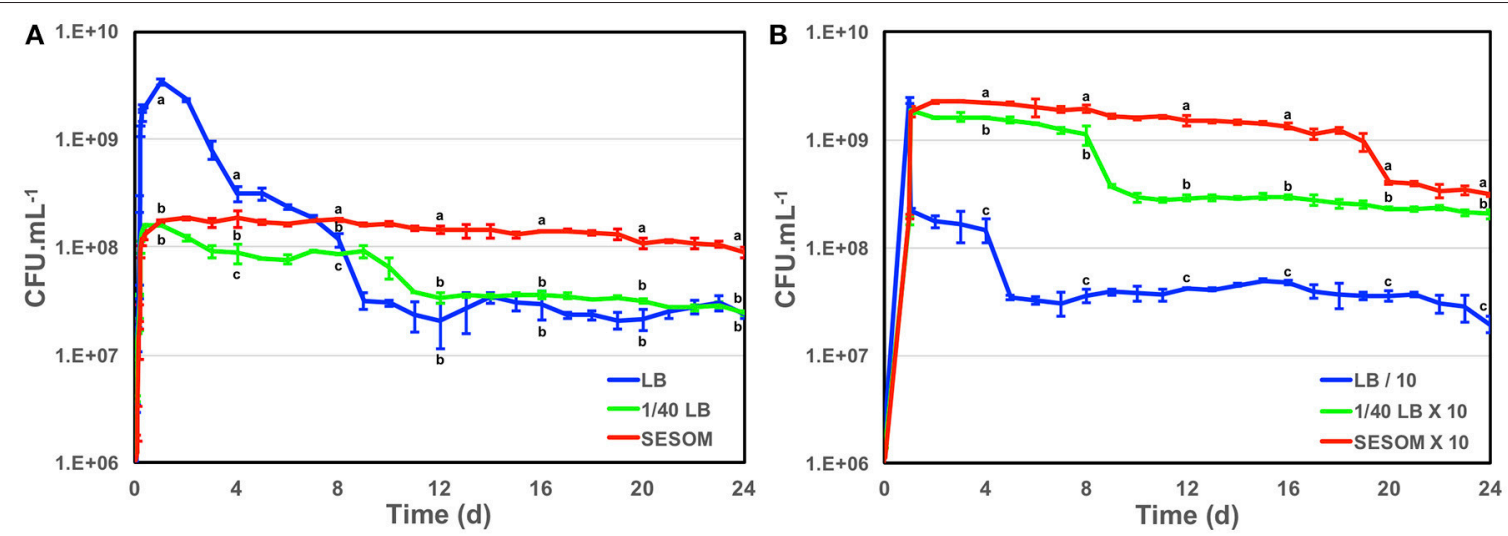

FIGURE 2 | Growth and survival of E. coli O157:H7 933D in LB, dilute LB (1/40) and SESOM (A), and when cultures were either concentrated 10-fold in own supernatant (SESOM and 1/40th LB-grown), or diluted 10-fold (LB-grown) at $24 \mathrm{~h} \mathrm{(B).} \mathrm{Error} \mathrm{bars} \mathrm{indicate} \mathrm{one} \mathrm{standard} \mathrm{error} \mathrm{of} \mathrm{the} \mathrm{mean.} \mathrm{Different} \mathrm{letters} \mathrm{at} \mathrm{the} \mathrm{same}$ time point indicate significant difference as determined by ANOVA test with multiple LSD comparisons.
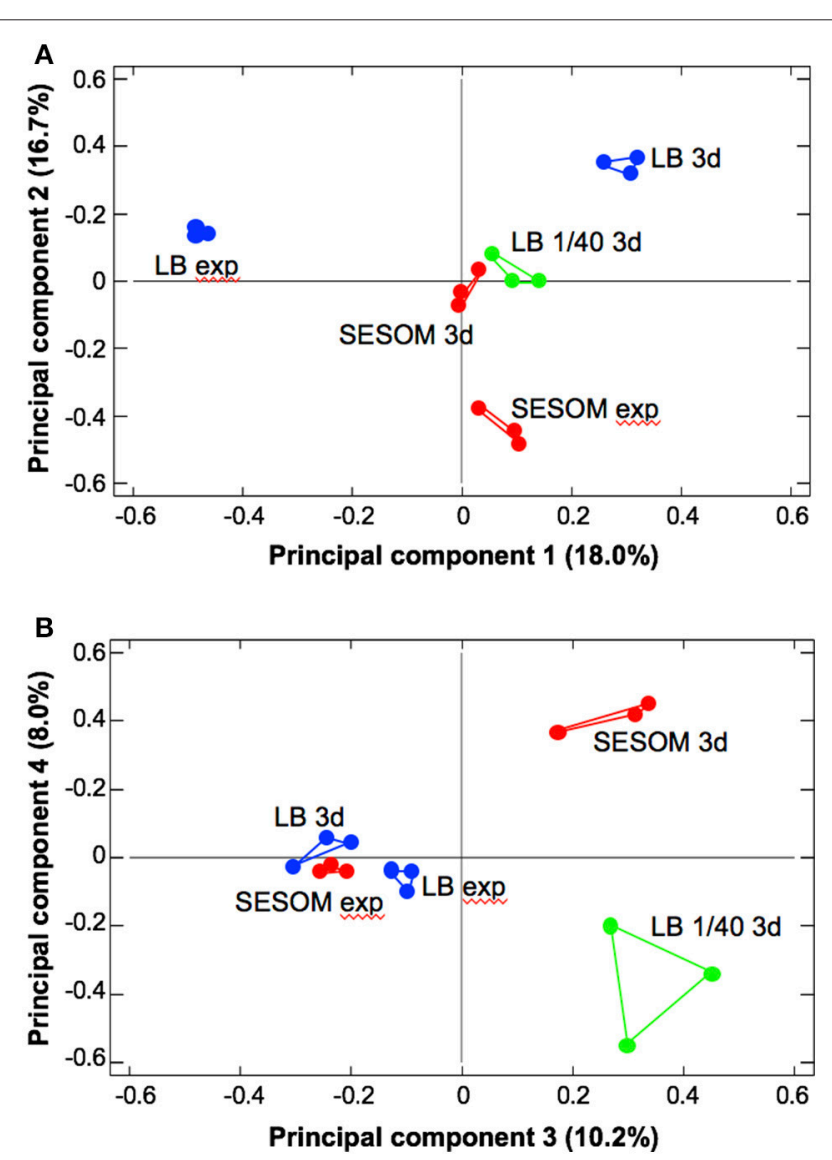

FIGURE 3 | Principle component analysis of exponential (exp) and stationary phase (3d) proteomes of E. coli O157:H7 933D cultured in LB, 1/40strength $\mathrm{LB}$ and $\mathrm{SESOM}$ at $30^{\circ} \mathrm{C}$. Four components with Eigen values $>1$ were revealed, shown as principle components 1 and 2 (A) and 3 and 4 (B).

four coordinates, and quite different to the LB stationary phase proteome. Collectively the PCA analysis showed that stationary phase populations had culture medium-specific proteomes that could explain the different physiological states and propensity to survive.

A large number of protein spots had significantly different abundance as determined using the criteria outlined above in materials and methods. All these spots were identified by MALDI-TOF MS, and collectively paint a unique physiological state of E. coli O157:H7 persisting in soil organic matter (Table 1). Stationary phase LB populations appeared to experience several stresses as indicated by elevated levels of the universal stress protein UspA and the carbon starvation protein Slp. They also had elevated levels of the alkyl hydroperoxide reductase AhpC. By contrast SESOM-grown cells appeared less stressed and more active, indicated by increased levels in transcriptional (DksA and RpoA) and translational proteins (GroEL, TufA, and YeiP). This suggested sustained transcriptional and translational activity during stationary phase in SESOM vs. LB. Many uptake systems were either over or under-expressed in SESOM-grown populations, including outer membrane and periplasmic uptake systems. This indicates that cells growing on SESOM have the ability to sense what the surrounding environment has to offer. These proteins reinforce the notion that E. coli O157:H7 is very adaptable to non-host environments such as soil. In addition to various uptake systems, several systems involving substrate metabolism were found to be over and under-expressed in SESOM-grown cells, indicating different approaches to catabolic activity in stationary phase.

Structurally, cells grown in SESOM appear to be different based on the expression of several membrane and cell structure proteins, primarily those involved in membrane lipid biosynthesis. YmcD and Adk were both up-regulated in SESOM. This suggests that the cellular envelope is formed differently in SESOM-grown populations as opposed to LB- or LB 1/40grown populations. Perhaps the cellular envelope is thicker to provide protection from adverse conditions. Both structural and regulatory flagellar proteins were present in increased abundance in SESOM-grown cells suggesting that the cells are potentially motile and responsive to chemotactic behavior in soil organic matter. Overall, SESOM-grown stationary phase cells 
TABLE 1 | Proteins of different abundance in stationary phase (3d) populations of $E$. coli $\mathrm{O} 157: \mathrm{H} 7$ grown and maintained in LB, 1/40-strength LB and SESOM at $30^{\circ} \mathrm{C}$.

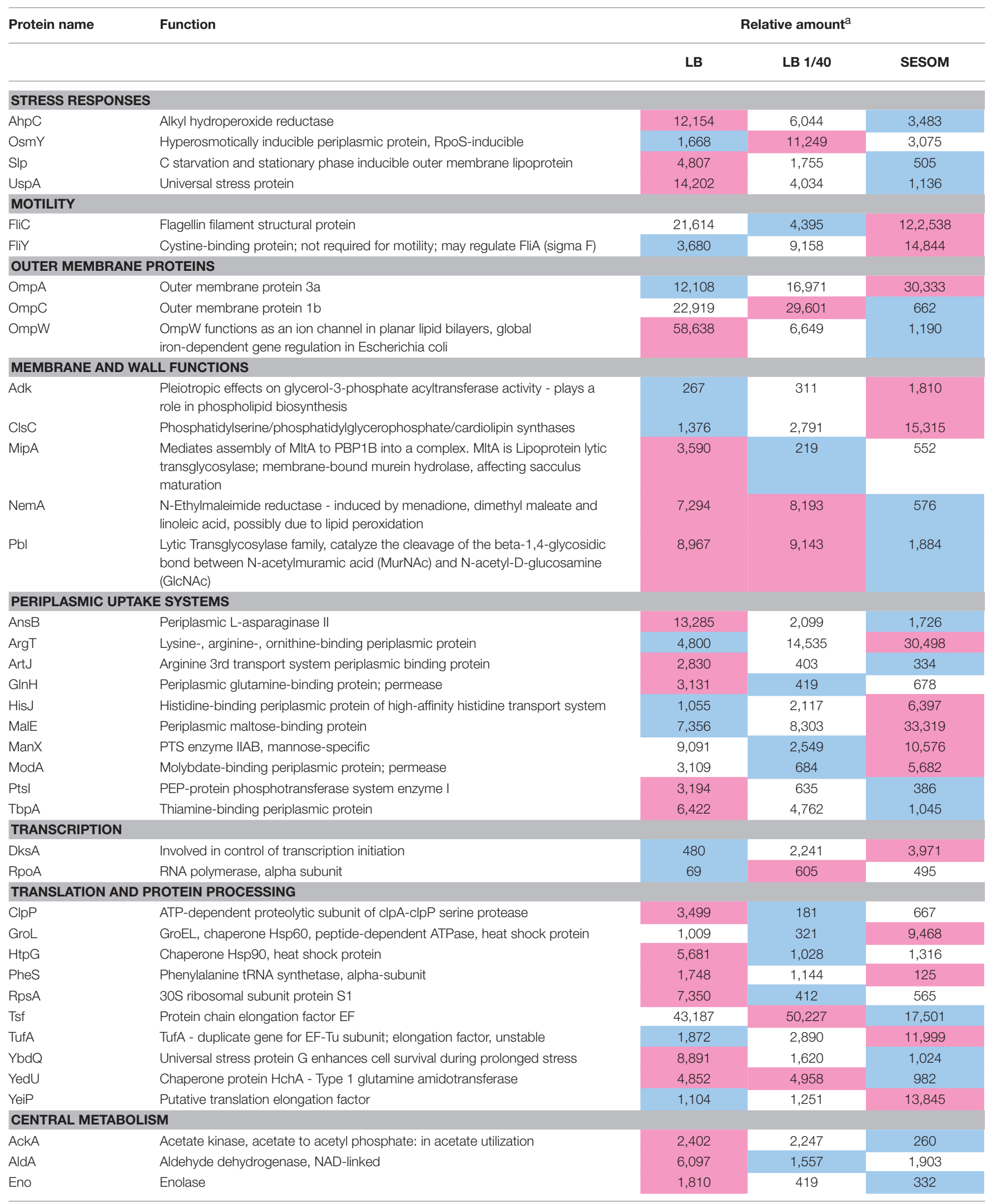


TABLE 1 | Continued

\begin{tabular}{|c|c|c|c|c|}
\hline \multirow[t]{2}{*}{ Protein name } & \multirow[t]{2}{*}{ Function } & \multicolumn{3}{|c|}{ Relative amount ${ }^{\mathrm{a}}$} \\
\hline & & LB & LB $1 / 40$ & SESOM \\
\hline Lcd & Isocitrate dehydrogenase, specific for NADP+ & 9,996 & 287 & 433 \\
\hline LpcA & Phosphoheptose isomerase & 1,144 & 126 & 595 \\
\hline Lpd & $\begin{array}{l}\text { Subunit of various ezymes: dihydrolipoate dehydrogenase, } 2 \text { oxoglutare } \\
\text { dehydrogenase and pyruvate dehydrogenase }\end{array}$ & 4,928 & 5,364 & 1,148 \\
\hline MaeB & Putative NADP+-linked malic enzyme & 1,878 & 2,983 & 438 \\
\hline Mdh & Malate dehydrogenase & 863 & 1,346 & 5,757 \\
\hline PckA & Phosphoenolpyruvate carboxykinase & 1,994 & 2,875 & 749 \\
\hline Pgk & Phosphoglycerate kinase & 272 & 424 & 9,162 \\
\hline PpsA & Phosphoenolpyruvate synthase & 2,972 & 1,017 & 620 \\
\hline YfiD & Putative formate acetyltransferase & 3,946 & 590 & 748 \\
\hline \multicolumn{5}{|c|}{ ATPase FUNCTION } \\
\hline AtpA & Membrane-bound ATP synthase, F1 sector, alpha-subunit & 31,963 & 31,551 & 3,123 \\
\hline AtpH & Membrane-bound ATP synthase, F1 sector, delta-subunit & 5,737 & 207 & 255 \\
\hline Ppa & Inorganic pyrophosphatase - hydrolyzes diphosphate to $2 \mathrm{Pi}$ & 11,687 & 677 & 2,019 \\
\hline \multicolumn{5}{|c|}{ AMINO ACID BIOSYNTHESIS } \\
\hline Aspa & Aspartate ammonia-lyase (aspartase) & 17,030 & 3,517 & 2,553 \\
\hline Cysk & Cysteine synthase A, O-acetylserine sulfhydrolase A & 1,812 & 5,513 & 4,567 \\
\hline FkIB & Peptidyl-prolyl cis-trans isomerase & 9,539 & 635 & 1,158 \\
\hline GcvT & $\begin{array}{l}\text { Aminomethyltransferase (tetrahydrofolate-dependent) of glycine cleavage } \\
\text { system }\end{array}$ & 4,291 & 828 & 773 \\
\hline AcrA & Acridine efflux pump, related to MAR system & 7,322 & 214 & 1,496 \\
\hline Hha & Modulates expression of haemolysin genes hly & 1,328 & 3,285 & 4,941 \\
\hline PmbA & Antibiotic peptide MccB17 & 10,512 & 29,643 & 25,983 \\
\hline TerZ & Putative phage inhibition, colicin resistance and tellurite resistance protein & 4,970 & 119 & 962 \\
\hline TolB & $\begin{array}{l}\text { Periplasmic protein involved in the tonB-independent uptake of group A } \\
\text { colicins }\end{array}$ & 4,304 & 927 & 363 \\
\hline FolA & Dihydrofolate reductase type I; trimethoprim resistance & 187 & 482 & 1,461 \\
\hline \multicolumn{5}{|c|}{ MISCELLANEOUS } \\
\hline $\mathrm{CcmH}$ & Required for synthesis of c-type cytochromes & 71 & 479 & 756 \\
\hline $\mathrm{NrdH}$ & $\begin{array}{l}\text { Glutaredoxin-like protein involved in electron transport system for } \\
\text { ribonucleotide reductase system NrdEF }\end{array}$ & 5,360 & 492 & 325 \\
\hline RibB & 3,4 dihydroxy-2-butanone-4-phosphate synthase - riboflavin biosynthesis & 544 & 2,255 & 4,423 \\
\hline CchA & Putative acetyl/butyryl P transferase & 124 & 82 & 1,069 \\
\hline NohB & Putative DNA packaging protein of prophage CP-933R & 2,689 & 528 & 708 \\
\hline \multicolumn{5}{|c|}{ UNKNOWN FUNCTION } \\
\hline YbiM & Unknown Hypothetical protein & 1,131 & 228 & 2,423 \\
\hline YdcL & Predicted lipoprotein & 857 & 3,147 & 171 \\
\hline YidQ & Putative periplasmic lipoprotein & 5,199 & 769 & 398 \\
\hline
\end{tabular}

The highest of three abundances is highlighted in red, and the lowest in blue.

${ }^{a}$ The relative amount is the average normalized amount of protein per spot across three separate gels. 
appeared less stressed, more motile, metabolically different, and with suggestions of less altered membrane composition when compared to LB-grown populations.

\section{DISCUSSION}

E. coli is not thought to survive for long periods outside the host intestine, so produce-associated outbreaks have widely been ascribed to recent fecal contamination. The suspected sources of produce contamination include soil amendments (manure or compost), irrigation water contaminated with cattle feces, or contaminated surface runoff (Ongeng et al., 2015). Our results showed that E. coli O157 can grow using nutrients available in soils (Figure 1). There have been countless studies reporting numbers of $E$. coli $\mathrm{O} 157$ in soils over time, and some have suggested growth in soil. Survival of E. coli in soil has been reported by many researchers; more than $200 \mathrm{~d}$ under natural environmental conditions and $500 \mathrm{~d}$ in frozen soil and on plant roots (Gagliardi and Karns, 2002; Islam et al., 2004). This is the first report showing definitively that E. coli $\mathrm{O} 157$ is able to grow using water soluble nutrients in soil.

Soil-grown E. coli $\mathrm{O} 157$ appeared more resilient than laboratory-grown cultures, with almost $100 \%$ culturability maintained over $28 \mathrm{~d}$ (Figure 2). This finding pointed to an altered physiological state of SESOM-grown cells entering stationary phase. This suggests that $E$. coli responds differently to nutrient limitation in SESOM, preparing cells for stationary phase differently. To gain insight into possible physiological reasons underlying the extended longevity of SESOM-grown populations, the proteomes of LB and SESOM-grown stationary phase cultures were compared (Table 1). The stationary phase proteome of SESOM-grown E. coli differed significantly from LBgrown and dilute LB-grown populations (Figure 3), indicating cells with substantially altered composition, and therefore catalytic and structural properties.

SESOM grown cells had lower levels of several proteins associated with cellular responses to stress, including Alkyl hydroperoxide reductase (AhpC), the carbon starvation response lipoprotein Slp, and the universal stress protein UspA (Table 1). AhpC is the primary degrader of hydrogen peroxide and reactive nitrogen intermediates in $E$. coli, protecting the cell against oxidative stresses (Chen et al., 1998). The substantially lower concentration of AhpC in SESOM-grown cells indicated decreased oxidative stress, or possible alternative mechanisms to cope with reactive oxygen and nitrogen species. Slp accumulates in response to carbon starvation (Alexander and St John, 1994), but our data showed that LB grown cells expressed the most Slp, although SESOM-grown cells were clearly nutrient starved following entry in stationary phase (Liebeke et al., 2009). Clearly, SESOM-grown cells responded differently to nutrient starvation and entry in stationary phase. UspA is induced as soon as the growth rate falls below the maximum rate supported by the medium (Nyström and Neidhardt, 1994). Despite the abrupt transition from exponential to stationary phase in SESOM, cells expressed less UspA than in LB. SESOM populations contained a much greater amount of the flagellar components FliC and FliY, indicating increased motility.

OmpA, the major outer membrane protein in E. coli, was more prevalent in the SESOM population. Loss of OmpC in E. coli contributes to antibiotic resistance (Liu et al., 2012), but this is only significant in the exponential-phase, while such difference in stress-resistance becomes trivial after bacteria reach the stationary phase (Wang, 2002). The elevated OmpA in LB populations is likely due to the high $\mathrm{NaCl}$ concentration. The ratio of $\mathrm{OmpC}$ to $\mathrm{OmpF}$ increases at higher temperature and $\mathrm{pH}$, as well as under oxidative stress (Snyder et al., 2013), consistent with increased level of AhpC in LB cells. Elevated levels of Adk and $\mathrm{ClsC}$ indicated differences in membrane lipid composition of SESOM vs. LB-grown populations due to their role in synthesis of phospholipids. An addition, Adk has been linked to mutational fitness effects. It was also observed that the length of the lag phase is more sensitive to variation in Adk catalytic capacity than is the exponential growth rate, so that the lag phase appears to be optimal with respect to variation in Adk catalytic capacity (Adkar et al., 2017). NemA, abundant in LB cultures, is involved in reductive degradation of toxic nitrous compounds (Umezawa et al., 2008), again consistent with elevated AhpC in LB populations. Enhanced levels of the peptidoglycan-modulating factors MipA and Pbl in LB cultures indicates differences in cell wall structure between the stationary phase cultures. High levels of MipA have been reported in sessile compared to planktonic cultures (Rivas et al., 2008).

Periplasmic nutrient uptake systems varied in quantity across the three culture media, but would be remnants from exponential phase where amino acid and sugar uptake were required. The high levels of AnsB, ArtJ, and GlnH in LB cultures is puzzling as LB supplies ample amino acids derived from tryptone and yeast extract. Our forest SESOM did not contain detectable levels of lysine, arginine, ornithine or histidine (Liebeke et al., 2009), explaining the enhanced level of ArgT and HisJ. ArgT expression is increased in response to nitrogen starvation and during early response glucose limitation (Kabir et al., 2004; Franchini and Egli, 2006), and our SESOM contained very little glucose. Molybdenum (molybdate) is essential as cofactor for the assembly and function of several enzymes including nitrate reductase, formate dehydrogenase, dimethylsulfoxide reductase, trimethylamine-N-oxide reductase, and biotin-sulfoxide reductase (Rajagopalan and Johnson, 1992). PtsI, more prevalent in LB, is a component of the glucose uptake system that is inhibited by $\alpha$-ketoglutarate during nitrogen limitation, when it was over expressed the metabolic rate was increased 4-fold (Chubukov et al., 2017).

DksA was highly expressed in SESOM grown cells, suggesting a stringent response with induction of ppGpp synthesis due to nutrient limitation. DksA activated by ppGpp binds to the $\beta$ subunit of RNA polymerase, directly affecting the affinity to different promoters and thus altering the expression level of more than 80 genes, most importantly suppression of all components of the protein biosynthesis system: rRNA, ribosomal proteins, and translation factors (Pletnev et al., 2015). This indicates that transcription is shut down tightly in SESOM-grown stationary phase cells. 
LB populations appeared more stressed as indicated by elevated levels of various stress proteins and chaperones. LB populations contained more ClpP, part of the proteosomal protein degradation system. Controlled degradation of cytoplasmic proteins has long been considered essential for survival of bacteria under stress conditions, due to the requirement for efficient removal of misfolded or otherwise damaged proteins by ClpP (Weichart et al., 2003). The corresponding low abundance of ClpP in cultures with no decline phase indicated either a reduced need for protein turnover, or a lower degree of damaged proteins. A different profile of damaged proteins was supported by the differences in chaperones GroL (SESOM and 1/40 LB) and HtpG (LB). HtpG expression is increased in cells grown in a complex medium with ample amino acid availability (LB) following heat shock, but low in glucose minimal medium. HtpG expression was unaffected or even repressed by imposition of a nutrient stress condition in minimal medium (Mason et al., 1999). The stressed nature of LB stationary cells was supported by elevated levels of Tsf (Elongation factor EF), which plays a role in sequestering surfaces of heterologous proteins to prevent protein-protein interactions leading to formation of inclusion bodies (Han et al., 2007). Elevated levels of the putative stress proteins YbdQ and YedU further indicated greater degree of stress in LB populations, as also indicated by alkyl hydroperoxide reductase. The elevated levels of TufA (Elongation factor $\mathrm{Tu}$ ) in SESOM indicates minor starvation due to nutrient limitation. TufA plays an important role in a minor starvation defense mechanism where it helps in rescuing stuck ribosomes (Pletnev et al., 2015).

A total of 17 central carbon metabolism enzymes were detected, and 14 of these were more abundant in LB, indicating that SESOM populations had prepared for reduced metabolic activity going into stationary phase. E. coli grown in rich medium undergo a reconstruction of their proteome in stationary phase, with increases in proteins required for scavenging and metabolizing rare nutrients and general cell protection (Li et al., 2014). An example was AckA (acetate kinase), part of the acetate switch that occurs as cells deplete their environment of acetate-producing carbon sources and scavenge for acetate. The accumulation of extracellular acetate during stationary phase occurs as cells co-metabolize acetogenic amino acids, e.g., l-threonine and l-alanine, with those that require the TCA cycle, e.g., L-glutamate (Wolfe, 2005). A second example was the elevated levels of ATP synthase components in LB populations, indicating continued need for ATP synthesis driven

\section{REFERENCES}

Adamowicz, M., Conway, T., and Nickerson, K. W. (1991). Nutritional complementation of oxidative glucose metabolism in Escherichia coli via pyrroloquinoline quinone-dependent glucose dehydrogenase and the EntnerDoudoroff pathway. Appl. Environ. Microbiol. 57, 2012-2015.

Adkar, B. V., Manhart, M., Bhattacharyya, S., Tian, J., Musharbash, M., and Shakhnovich, E. I. (2017). Optimization of lag phase shapes the evolution of a bacterial enzyme. Nat. Ecol. Evol. 1:149. doi: 10.1038/s41559-01 7-0149 by periplasmic proton motive force. A third example was PckA (phosphoenolpyruvate carboxykinase), elevated in LB and 1/40th LB. PckA increases 100-fold in the stationary phase independent of cyclic AMP, probably to provide carbohydrates required for energy reserves after cessation of growth, since protease activity, Krebs cycle enzyme activities, and glycogen synthesis all increase in the stationary phase (Goldie and Sanwal, 1980).

LB-grown populations had higher overall levels of amino acid biosynthetic enzymes, than both SESOM and dilute LB cultures. This contrasts with the abundance of metabolizable oligopeptides available in LB. However, bioassay of LB medium after growth of $E$. coli showed that it no longer contains significant amounts of recoverable L-serine, L-threonine, L-proline, L-glycine, Larginine, L-glutamine, L-asparagine, L-cysteine, and L-lysine (Sezonov et al., 2007), indicating a need for synthesis in stationary phase.

E. coli O157 933D appears well adapted to grow using soluble nutrients available in soil (SESOM). Moreover, SESOM grown populations did not display a detectable death phase, but remained culturable for at least $24 \mathrm{~d}$. This was supported by the substantially altered proteome of SESOM-grown stationary phase populations. Our results suggest that E. coli may well be a soil commensal that maintains stable populations in soil, as growth supported by soil nutrients combined with enhanced longevity of cells would help counter the effects of competition and predation. Soil itself should, therefore, be included as potential source of contamination of fresh produce. Future work should investigate the roles of competition and predation affecting E. coli populations in soil.

\section{AUTHOR CONTRIBUTIONS}

GN, AC, SV, and VB planned the research. GN, AC, and SV conducted the experiments. GN, SV, and VB analyzed the data. $\mathrm{GN}, \mathrm{AC}, \mathrm{SV}$, and VB wrote the paper.

\section{ACKNOWLEDGMENTS}

We thank David Francis for donating E. coli O157:H7 933D, and Birgit Voigt of the Institute for Microbiology, Ernst Moritz Arndt University, Greifswald, Germany for protein identification. GN and AC were supported by the South Dakota Agricultural Experiment Station. This research was supported by the South Dakota Agricultural Experiment Station. We acknowledge use of the SDSU-FGCF supported in part by NSF/EPSCoR Grant No. 0091948 and by the State of South Dakota. membrane lipoprotein in Escherichia coli. Mol. Microbiol. 11, 1059-1071. doi: 10.1111/j.1365-2958.1994.tb00383.x

Berry, E. D., and Miller, D. N. (2005). Cattle feedlot soil moisture and manure content: II. Impact on Escherichia coli O157. J. Environ. Qual. 34, 656-663. doi: 10.2134/jeq2005.0656

Brandl, M. T. (2008). Plant lesions promote the rapid multiplication of Escherichia coli O157:H7 on postharvest lettuce. Appl. Environ. Microbiol. 74, 5285-5289. doi: 10.1128/AEM.01073-08 
Byappanahalli, M. N., Whitman, R. L., Shively, D. A., Sadowsky, M. J., and Ishii, S. (2006). Population structure, persistence, and seasonality of autochthonous Escherichia coli in temperate, coastal forest soil from a Great Lakes watershed. Environ. Microbiol. 8, 504-513. doi: 10.1111/j.1462-2920.2005.00916.x

Chen, L., Xie, Q. W., and Nathan, C. (1998). Alkyl hydroperoxide reductase subunit $\mathrm{C}(\mathrm{AhpC})$ protects bacterial and human cells against reactive nitrogen intermediates. Mol. Cell 1, 795-805. doi: 10.1016/S1097-2765(00)80079-9

Chubukov, V., Desmarais, J. J., Wang, G., Chan, L. J. G., Baidoo, E. E. K., Petzold, C. J., et al. (2017). Engineering glucose metabolism of Escherichia coli under nitrogen starvation. NPJ Syst. Biol. Appl. 3:16035. doi: 10.1038/npjsba.2016.35

Currie, A., NacDonald, J., Ellis, A., Siushansian, J., Chui, L., Charlebois, M., et al. (2007). Outbreak of Escherichia coli O157: H7 infections associated with consumption of beef donair. J. Food Prot. 70, 1483-1488. doi: 10.4315/0362-028X-70.6.1483

Denis, N., Zhang, H., Leroux, A., Trudel, R., and Bietlot, H. (2016). Prevalence and trends of bacterial contamination in fresh fruits and vegetables sold at retail in Canada. Food Control 67, 225-234. doi: 10.1016/j.foodcont.2016.02.047

Desmarais, T. R., Solo-Gabriele, H. M., and Palmer, C. J. (2002). Influence of soil on fecal indicator organisms in a tidally influenced subtropical environment. Appl. Environ. Microbiol. 68, 1165-1172. doi: 10.1128/AEM.68.3.1165-1172.2002

Fagan, P. K., Hornitzky, M. A., Bettelheim, K. A., and Djordjevic, S. P. (1999). Detection of shiga-like toxin (stx(1) and stx(2)), intimin (eaeA), and Enterohemorrhagic Escherichia coli (EHEC) hemolysin (EHEC hlyA) genes in animal feces by multiplex, P. C. R. Appl. Environ. Microbiol. 65, 868-872.

Franchini, A. G., and Egli, T. (2006). Global gene expression in Escherichia coli K12 during short-term and long-term adaptation to glucose-limited continuous culture conditions. Microbiology 152, 2111-2127. doi: 10.1099/mic.0.28939-0

Fremaux, B., Prigent-Combaret, C., Delignette-Muller, M. L., Mallen, B., Dothal, M., Gleizal, A., et al. (2008). Persistence of Shiga toxin-producing Escherichia coli $\mathrm{O} 26$ in various manure-amended soil types. J. Appl. Microbiol. 104, 296-304. doi: 10.1111/j.1365-2672.2007.03532.x

Gagliardi, J. V., and Karns, J. S. (2002). Persistence of Escherichia coli O157: H7 in soil and on plant roots. Environ. Microbiol. 4, 89-96. doi: 10.1046/j.1462-2920.2002.00273.x

Goldie, A. H., and Sanwal, B. D. (1980). Genetic and physiological characterization of Escherichia coli mutants deficient in phosphoenolpyruvate carboxykinase activity. J. Bacteriol. 141, 1115-1121.

Grant, J., Wendelboe, A. M., Wendel, A., Jepson, B., Torres, P., Smelser, C., et al. (2008). Spinach-associated Escherichia coli O157:H7 outbreak, Utah and New Mexico, (2006). Emerg. Infect. Dis. 14, 1633-1636. doi: 10.3201/eid1410.071341

Guggenberger, G., and Zech, W. (1993a). Dissolved organic carbon control in acid forest soils of the Fichtelgebirge (Germany) as revealed by distribution patterns and structural composition analyses. Geoderma 59, 109-129. doi: 10.1016/0016-7061(93)90065-S

Guggenberger, G., and Zech, W. (1993b). Dissolved Organic-Matter (Dom) dynamics in spruce forested sites - examinations by analytical dom fractionation. Z Pflanz Bodenkunde 156, 341-347. doi: 10.1002/jpln.19931560411

Han, K. Y., Song, J. A., Ahn, K. Y., Park, J. S., Seo, H. S., and Lee, J. (2007). Enhanced solubility of heterologous proteins by fusion expression using stressinduced Escherichia coli protein, Tsf. FEMS Microbiol. Lett. 274, 132-138. doi: 10.1111/j.1574-6968.2007.00824.x

Herman, K. M., Hall, A. J., and Gould, L. H. (2015). Outbreaks attributed to fresh leafy vegetables, United States, 1973-2012. Epidemiol. Infect. 143, 3011-3021. doi: 10.1017/S0950268815000047

Hilborn, E. D., Mermin, J. H., Mshar, P. A., Hadler, J. L., Voetsch, A., Wojtkunski, C., et al. (1999). A multistate outbreak of Escherichia coli O157:H7 infections associated with consumption of mesclun lettuce. Arch. Intern. Med. 159, 1758-1764. doi: 10.1001/archinte.159.15.1758

Huang, Y., Eglinton, G., Van Der Hage, E. R. E., Boon, J. J., Bol, R., and Ineson, P. (1998). Dissolved organic matter and its parent organic matter in grass upland soil horizons studied by analytical pyrolysis techniques. Eur. J. Soil Sci. 49, 1-15. doi: 10.1046/j.1365-2389.1998.00141.x

Ishii, S., Ksoll, W. B., Hicks, R. E., and Sadowsky, M. J. (2006). Presence and growth of naturalized Escherichia coli in temperate soils from Lake Superior watersheds. Appl. Environ. Microbiol. 72, 612-621. doi: 10.1128/AEM.72.1.612-621.2006
Islam, M., Doyle, M. P., Phatak, S. C., Millner, P., and Jiang, X. P. (2004). Persistence of enterohemorrhagic Escherichia coli O157: H7 in soil and on leaf lettuce and parsley grown in fields treated with contaminated manure composts or irrigation water. J. Food Prot. 67, 1365-1370. doi: 10.4315/0362-028X-67.7.1365

Jones, D. L., Kemmitt, S. J., Wright, D., Cuttle, S. P., Bol, R., and Edwards, A. C. (2005). Rapid intrinsic rates of amino acid biodegradation in soils are unaffected by agricultural management strategy. Soil Biol. Biochem. 37, 1267-1275. doi: 10.1016/j.soilbio.2004.11.023

Kabir, M. S., Sagara, T., Oshima, T., Kawagoe, Y., Mori, H., Tsunedomi, R., et al. (2004). Effects of mutations in the rpoS gene on cell viability and global gene expression under nitrogen starvation in Escherichia coli. Microbiol 150, 2543-2553. doi: 10.1099/mic.0.27012-0

Kaiser, K., Guggenberger, G., Haumaier, L., and Zech, W. (2001). Seasonal variations in the chemical composition of dissolved organic matter in organic forest floor layer leachates of old-growth Scots pine (Pinus sylvestris L.) and European beech (Fagus sylvatica L.) stands in northeastern Bavaria, Germany. Biogeochemistry 55, 103-143. doi: 10.1023/A:1010694032121

Kalbitz, K., Schwesig, D., Schmerwitz, J., Kaiser, K., Haumaier, L., Glaser, B., et al. (2003). Changes in properties of soil-derived dissolved organic matter induced by biodegradation. Soil Biol. Biochem. 35, 1129-1142. doi: 10.1016/S0038-0717(03)00165-2

Kalbitz, K., Solinger, S., Park, J. H., Michalzik, B., and Matzner, E. (2000). Controls on the dynamics dissolved organic matter in soils: a review. Soil Sci. 165, 277-304. doi: 10.1097/00010694-200004000-00001

King, L. A., Mailles, A., Mariani-Kurkdjian, P., Vernozy-Rozand, C., Montet, M. P., Grimont, F., et al. (2009). Community-wide outbreak of Escherichia coli O157:H7 associated with consumption of frozen beef burgers. Epidemiol. Infect. 137, 889-896. doi: 10.1017/S0950268808001490

Ksoll, W. B., Ishii, S., Sadowsky, M. J., and Hicks, R. E. (2007). Presence and sources of fecal coliform bacteria in epilithic periphyton communities of Lake Superior. Appl. Environ. Microbiol. 73, 3771-3778. doi: 10.1128/AEM.02654-06

LeBlanc, J. J. (2003). Implication of virulence factors in Escherichia coli O157: H7 pathogenesis. Crit. Rev. Microbiol. 29, 277-296. doi: 10.1080/713608014

Li, Z. P., Nimtz, M., and Rinas, U. (2014). The metabolic potential of Escherichia coli BL21 in defined and rich medium. Microb. Cell Fact. 13:45. doi: 10.1186/1475-2859-13-45

Liebeke, M., Brözel, V. S., Hecker, M., and Lalk, M. (2009). Chemical characterization of soil extract as growth media for the ecophysiological study of bacteria. Appl. Microbiol. Biotechnol. 83, 161-173. doi: 10.1007/s00253-009-1965-0

Lindsay, D., and von Holy, A. (1999). Different responses of planktonic and attached Bacillus subtilis and Pseudomonas fluorescens to sanitizer treatment. J. Food Prot. 62, 368-379. doi: 10.4315/0362-028X-62.4.368

Liu, Y. F., Yan, J. J., Lei, H. Y., Teng, C. H., Wang, M. C., Tseng, C. C., et al. (2012). Loss of outer membrane protein C in Escherichia coli contributes to both antibiotic resistance and escaping antibody-dependent bactericidal activity. Infect. Immun. 80, 1815-1822. doi: 10.1128/IAI.06395-11

Looper, M. L., Edrington, T. S., Callaway, T. R., and Rosenkrans, C. F. Jr. (2009). Fate of Escherichia coli O157:H7 and Salmonella from contaminated manure slurry applied to soil surrounding tall fescue. Lett. Appl. Microbiol. 48, 513-516. doi: 10.1111/j.1472-765X.2009.02563.x

Lynch, J. M. (1982). Limits to microbial-growth in Soil. J. Gen. Microbiol. 128, 405-410. doi: 10.1099/00221287-128-2-405

Mason, C. A., Dünner, J., Indra, P., and Colangelo, T. (1999). Heat-induced expression and chemically induced expression of the Escherichia coli stress protein HtpG Are affected by the growth environment. Appl. Environ. Microbiol. 65, 3433-3440.

NandaKafle, G., Seale, T., Flint, T., Nepal, M., Venter, S. N., and Brozel, V. S. (2017). Distribution of diverse Escherichia coli between cattle and pasture. Microbes Environ. 32, 226-233. doi: 10.1264/jsme2.ME17030

Nyström, T., and Neidhardt, F. C. (1994). Expression and role of the universal stress protein, UspA, of Escherichia coli during growth arrest. Mol. Microbiol. 11, 537-544. doi: 10.1111/j.1365-2958.1994.tb00334.x

O’Brien, A. D., Marques, L. R. M., Kerry, C. F., Newland, J. W., and Holmes, R. K. (1989). Shiga-like toxin converting phage of enterohemorrhagic Escherichia coli strain 933. Microb. Pathog. 6, 381-390. doi: 10.1016/0882-4010(89)90080-6 
Ongeng, D., Geeraerd, A. H., Springael, D., Ryckeboer, J., Muyanja, C., and Mauriello, G. (2015). Fate of Escherichia coli O157:H7 and Salmonella enterica in the manure-amended soil-plant ecosystem of fresh vegetable crops: a review. Crit. Rev. Microbiol. 41, 273-294. doi: 10.3109/1040841X.2013.829415

Pizzeghello, D., Zanella, A., Carletti, P., and Nardi, S. (2006). Chemical and biological characterization of dissolved organic matter from silver fir and beech forest soils. Chemosphere 65, 190-200. doi: 10.1016/j.chemosphere.2006.03.001

Pletnev, P., Osterman, I., Sergiev, P., Bogdanov, A., and Dontsova, O. (2015). Survival guide: Escherichia coli in the stationary phase. Acta Nat. 7, 22-33.

Rabilloud, T. (1992). A comparison between low background silver diammine and silver nitrate protein stains. Electrophoresis 13, 429-439. doi: 10.1002/elps.1150130190

Rajagopalan, K. V., and Johnson, J. L. (1992). The pterin molybdenum cofactors. J. Biol. Chem. 267, 10199-10202.

Rivas, L., Fegan, N., and Dykes, G. A. (2008). Expression and putative roles in attachment of outer membrane proteins of Escherichia coli 0157 from planktonic and sessile culture. Foodborne Pathog. Dis. 5, 155-164. doi: 10.1089/fpd.2007.0052

Schneckenberger, K., Demin, D., Stahr, K., and Kuzyakov, Y. (2008). Microbial utilization and mineralization of $\left[{ }^{14} \mathrm{C}\right]$ glucose added in six orders of concentration to soil. Soil Biol. Biochem. 40, 1981-1988. doi: 10.1016/j.soilbio.2008.02.020

Sezonov, G., Joseleau-Petit, D., and D'Ari, R. (2007). Escherichia coli physiology in Luria-Bertani broth. J. Bacteriol. 189, 8746-8749. doi: 10.1128/JB.01368-07

Snyder, L., Peters, J. E., Henkin, T. M., and Champness, W. (2013). Molecular Genetics of Bacteria, 4th Edn. Washington, DC: American Society of Microbiology.

Strobel, B. W. (2001). Influence of vegetation on low-molecular-weight carboxylic acids in soil solution - a review. Geoderma 99, 169-198. doi: 10.1016/S0016-7061(00)00102-6

Strockbine, N. A., Marques, L. R., Newland, J. W., Smith, H. W., Holmes, R. K., and O'Brien, A. D. (1986). Two toxin-converting phages from Escherichia coli O157:H7 strain 933 encode antigenically distinct toxins with similar biologic activities. Infect. Immun. 53, 135-140.

Tallon, P., Magajna, B., Lofranco, C., and Leung, K. T. (2005). Microbial indicators of faecal contamination in water: a current perspective. Water Air Soil Pollut. 166, 139-166. doi: 10.1007/s11270-005-7905-4

Umezawa, Y., Shimada, T., Kori, A., Yamada, K., and Ishihama, A. (2008). The uncharacterized transcription factor YdhM is the regulator of the nemA gene, encoding N-ethylmaleimide reductase. J. Bacteriol. 190, 5890-5897. doi: 10.1128/JB.00459-08

Van Hees, P. A. W., Jones, D. L., Finlay, R., Godbold, D. L., and Lundstromd, U. S. (2005). The carbon we do not see - the impact of low molecular weight compounds on carbon dynamics and respiration in forest soils: a review. Soil Biol. Biochem. 37, 1-13. doi: 10.1016/j.soilbio.2004.06.010

Vilain, S., and Brözel, V. S. (2006). Multivariate approach to comparing whole-cell proteomes of Bacillus cereus indicates a biofilm-specific proteome. J. Proteome Res. 5, 1924-1930. doi: 10.1021/pr050402b

Vilain, S., Cosette, P., Charlionet, R., Hubert, M., Lange, C., Junter, G. A., et al. (2001). Substituting coomassie brilliant blue for bromophenol blue in two-dimensional electrophoresis buffers improves the resolution of focusing patterns. Electrophoresis 22, 4368-4374. doi: 10.1002/1522-2683(200112)22:20<4368::AID-ELPS4368>3.0.CO;2-9

Vilain, S., Luo, Y., Hildreth, M. B., and Brözel, V. S. (2006). Analysis of the life cycle of the soil saprophyte Bacillus cereus in liquid soil extract and in soil. Appl. Environ. Microbiol. 72, 4970-4977. doi: 10.1128/AEM. 03076-05

Vital, M., Hammes, F., and Egli, T. (2008). Escherichia coli O157 can grow in natural freshwater at low carbon concentrations. Environ. Microbiol. 10, 2387-2396. doi: 10.1111/j.1462-2920.2008.01664.x

Voigt, B., Schweder, T., Sibbald, M. J. J. B., Albrecht, D., Ehrenreich, A., Bernhardt, J., et al. (2006). The extracellular proteome of Bacillus licheniformis grown in different media and under different nutrient starvation conditions. Proteomics 6, 268-281. doi: 10.1002/pmic.200500091

Wang, O., McAllister, T. A., Plastow, G., Stanford, K., Selinger, B., and Guan, L. L. (2017). Host mechanisms involved in cattle Escherichia coli O157 shedding: a fundamental understanding for reducing foodborne pathogen in food animal production. Sci. Rep. 7:7630. doi: 10.1038/s41598-01706737-4

Wang, Y. (2002). The function of OmpA in Escherichia coli. Biochem. Biophys. Res. Commun. 292, 396-401. doi: 10.1006/bbrc.2002.6657

Weichart, D., Querfurth, N., Dreger, M., and Hengge-Aronis, R. (2003). Global role for ClpP-containing proteases in stationary-phase adaptation of Escherichia coli. J. Bacteriol. 185, 115-125. doi: 10.1128/JB.185.1.115-125.2003

Williams, A. P., McGregor, K. A., Killham, K., and Jones, D. L. (2008). Persistence and metabolic activity of Escherichia coli O157:H7 in farm animal faeces. FEMS Microbiol. Lett. 287, 168-173. doi: 10.1111/j.1574-6968.2008. 01310.x

Winfield, M. D., and Groisman, E. A. (2003). Role of nonhost environments in the lifestyles of Salmonella and Escherichia coli. Appl. Environ. Microbiol. 69, 3687-3694. doi: 10.1128/AEM.69.7.3687-3694.2003

Wolfe, A. J. (2005). The acetate switch. Microbiol. Mol. Biol. Rev. 69, 12-50. doi: 10.1128/MMBR.69.1.12-50.2005

Wright, K. M., Chapman, S., McGeachy, K., Humphris, S., Campbell, E., Toth, I. K., et al. (2013). The endophytic lifestyle of Escherichia coli O157:H7: quantification and internal localization in roots. Phytopathology 103, 333-340. doi: 10.1094/PHYTO-08-12-0209-FI

Wright, K. M., Crozier, L., Marshall, J., Merget, B., Holmes, A., and Holden, N. J. (2017). Differences in internalization and growth of Escherichia coli O157:H7 within the apoplast of edible plants, spinach and lettuce, compared with the model species Nicotiana benthamiana. Microb. Biotechnol. 10, 555-569. doi: 10.1111/1751-7915.12596

Yang, S. C., Lin, C. H., Aljuffali, I. A., and Fang, J. Y. (2017). Current pathogenic Escherichia coli foodborne outbreak cases and therapy development. Arch. Microbiol. 199, 811-825. doi: 10.1007/s00203-017-1393-y

Yoon, J. W., and Hovde, C. J. (2008). All blood, No stool: enterohemorrhagic Escherichia coli O157: H7 infection. J. Vet. Sci. 9, 219-231. doi: $10.4142 /$ jvs.2008.9.3.219

Conflict of Interest Statement: The authors declare that the research was conducted in the absence of any commercial or financial relationships that could be construed as a potential conflict of interest.

Copyright (c) 2018 NandaKafle, Christie, Vilain and Brözel. This is an open-access article distributed under the terms of the Creative Commons Attribution License (CC $B Y)$. The use, distribution or reproduction in other forums is permitted, provided the original author(s) and the copyright owner are credited and that the original publication in this journal is cited, in accordance with accepted academic practice. No use, distribution or reproduction is permitted which does not comply with these terms. 